\title{
The application of multi-criteria decision analysis to inform in
}

\section{resource allocation [version 1; peer review: 1 approved, 1}

\section{approved with reservations]}

\author{
Carina Schey (iD)1,2, Maarten Postma2-4, Paul Krabbe2, Goran Medic (iD2, \\ Mark Connolly ${ }^{1,2}$ \\ ${ }^{1}$ Global Market Access Solutions Sàrl, St-Prex, Switzerland \\ 2Department of Pharmacy, Unit of PharmacoTherapy, Epidemiology \& Economics, University of Groningen, Groningen, 9700 AB, The \\ Netherlands \\ ${ }^{3}$ Department of Health Sciences, University of Groningen - University Medical Center Groningen (UMCG), Groningen, 9700 AB, The \\ Netherlands \\ ${ }^{4}$ Department of Economics, Econometrics \& Finance, Faculty of Economics \& Business, University of Groningen, Groningen, 9700 AB, \\ The Netherlands
}

V1 First published: 26 May 2020, 9:445
https://doi.org/10.12688/f1000research.21728.1

Latest published: 26 May 2020, 9:445

https://doi.org/10.12688/f1000research.21728.1

\begin{abstract}
Background: There is a perception held by payers that orphan products are expensive. As a result, the current health technology assessment systems might be too restrictive for orphan drugs, therefore potentially denying patients access to life-saving medicines. While price is important, it should be considered in relation to a broader range of disease-related product attributes that are not necessarily considered by many health technology assessment agencies. To overcome these challenges, multi-criteria decision analysis has been proposed as an alternative to evaluate technologies. Methods: A targeted literature review was conducted to identify the most frequently cited attributes in multi-criteria decision analysis (MCDA) in rare diseases. From the leading attributes identified, we developed a multi-criteria decision analysis framework with which to aggregate the orphan drug values. We subsequently reviewed and plotted the relationship between single attributes and the average annual treatment costs for 8 drugs used in the treatment of rare endocrine diseases. The annual treatment costs were based on UK list prices for the average daily dose per patient.

Results: The five most frequently mentioned attributes in the literature were as follows: Disease severity, Unmet need (or availability of therapeutic alternatives), Comparative effectiveness or efficacy, Quality of evidence and Safety \& tolerability. Results from the multicriteria decision analysis framework indicate a wide range of average annual per-patients costs for drugs intended for the same diseases, and likewise for diseases with a similar level of Disease severity.
\end{abstract}

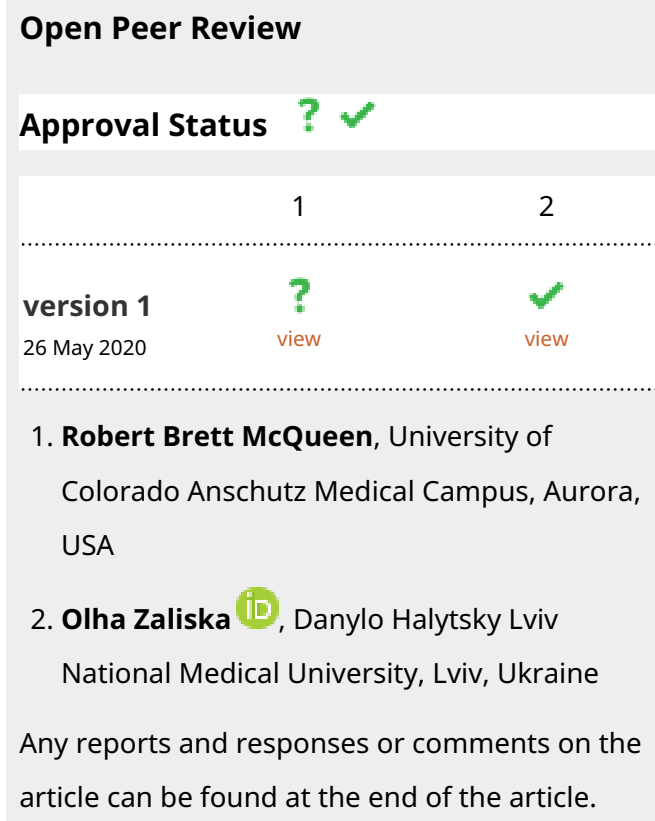

1

version 1

26 May 2020

$?$
view

2

1. Robert Brett McQueen, University of Colorado Anschutz Medical Campus, Aurora, USA

2. Olha Zaliska (D), Danylo Halytsky Lviv National Medical University, Lviv, Ukraine Any reports and responses or comments on the article can be found at the end of the article. 
Conclusions: Multi-criteria decision analysis may offer a viable alternative to support discussion in reimbursement decisions for orphan drugs. The analyses can be used to inform investigations on the application of MCDAs in rare diseases.

\section{Keywords}

orphan drug, multi-criteria decision analysis, criteria, attributes, healthcare, lysosomal storage disorders

\section{Corresponding author: Carina Schey (carina@gmasoln.com)}

Author roles: Schey C: Conceptualization, Data Curation, Formal Analysis, Methodology, Project Administration, Supervision, Validation, Visualization, Writing - Original Draft Preparation, Writing - Review \& Editing; Postma M: Conceptualization, Methodology, Supervision, Validation, Writing - Review \& Editing; Krabbe P: Methodology, Validation, Writing - Review \& Editing; Medic G: Data Curation, Formal Analysis, Validation, Writing - Review \& Editing; Connolly M: Conceptualization, Funding Acquisition, Investigation, Methodology, Project Administration, Supervision, Validation, Visualization, Writing - Review \& Editing

Competing interests: Prof Maarten J Postma has received grants and honoraria from various pharmaceutical companies in the past but unrelated to this manuscript. The other authors declare that they have no competing interests.

Grant information: The author(s) declared that no grants were involved in supporting this work.

Copyright: @ 2020 Schey C et al. This is an open access article distributed under the terms of the Creative Commons Attribution License, which permits unrestricted use, distribution, and reproduction in any medium, provided the original work is properly cited.

How to cite this article: Schey C, Postma M, Krabbe $\mathrm{P}$ et al. The application of multi-criteria decision analysis to inform in resource allocation [version 1; peer review: 1 approved, 1 approved with reservations] F1000Research 2020, 9:445 https://doi.org/10.12688/f1000research.21728.1

First published: 26 May 2020, 9:445 https://doi.org/10.12688/f1000research.21728.1 


\section{Abbreviations}

HTA, health technology assessment; MCDA, multi-criteria decision analysis; QALY, quality-adjusted life-year.

\section{Introduction}

The increasing demand on healthcare resources has created the need to minimize costs, resulting in more rigorous pricing and reimbursement pathways in most of Europe, potentially causing delays for patients to receive valuable treatments ${ }^{1}$. As the pressure on health technology assessment (HTA) bodies increases, so does the need to demonstrate the cost-effectiveness of orphan drugs. There is a perception among payers that orphan drugs are over-priced and therefore not cost-effective ${ }^{2}$. Patients have been refused access to drugs based on costeffectiveness perceptions that might possibly be linked to the application of cost-effectiveness thresholds ${ }^{3}$. The pharmaceutical media go to great lengths to highlight that orphan drugs are expensive interventions with costs being raised by the involvement of "big pharma" ${ }^{4,5}$. Therefore, orphan drugs are increasingly under scrutiny by health authorities as part of cost-containment initiatives and are frequently only reimbursed when negotiated under a patient access scheme $e^{6,7}$. The HTA processes are aimed at bridging the gap between evidence and healthcare policy and reimbursement decisions ${ }^{8}$. The current HTA systems adopted in many European countries may facilitate financial decisions that largely disregard disease impact on patients and a host of other disease-related attributes, and potentially ignore some unique features of innovative orphan drugs, thereby delaying or denying patients access to much needed treatments ${ }^{9-11}$. While the cost and budget impact of orphan drugs are important in relation to affordability, cost should be considered in relation to a broader range of drug- and disease-related attributes that are not necessarily considered in the usual HTA processes for most non-orphan drugs. This is increasingly problematic for markets linking costeffectiveness analysis to reimbursement decisions as the cost per quality-adjusted life-year (QALY) approach is not necessarily sensitive enough to capture the broader attributes of the therapy such as unmet need, disease severity, patient and societal preferences and other disease-related elements, possibly including disease rarity ${ }^{12}$.

Disease rarity implies that the level of clinical evidence and the uncertainty surrounding the treatment effectiveness generated in clinical trials is likely to differ from that of conventional diseases due to several key factors ${ }^{13}$. In particular, small heterogenous populations increase the level of uncertainty of the outcomes $^{14,15}$. In some rare diseases, there is limited natural history data and often a lack of consensus on the choice of treatment comparator and clinical endpoints ${ }^{16,17}$. Ethical constraints regarding placebo treatments in the control group when no other treatment options are available may arise ${ }^{15,18}$. Consequently, these factors might preclude a thorough analysis. Therefore, the likelihood of orphan drugs achieving the expected robust cost per QALY levels is limited ${ }^{19}$. Thus, the cost per QALY approach might not be optimal to assess the real value and benefits of orphan drugs and should, at least, not be the dominant tool to establish reimbursement.
In response to criticism regarding the variation in reimbursement decisions and potential inconsistent patient access to orphan drugs $^{20-22}$, the use of multi-criteria decision analysis (MCDA) has been proposed as a viable method for orphan drug assessments. The MCDA framework provides a consistent, transparent and accountable approach for the decision-making process for orphan drugs. The MCDA approach assumes that the value framework adopts clear criteria and that the criteria are weighted appropriately ${ }^{20,23}$. The premise is that because the framework is based on multiple criteria, it will provide a result that reflects not only the efficacy and cost of the drug, but also wider aspects such as disease severity, unmet need, patient's health-related quality of life and target patient age groups. Techniques for MCDA enable expert panels to perform "trade-offs" between multiple aspects and outcomes of a product against the product's cost as well as a combination of different criteria ${ }^{24}$. The Evidence and Value: Impact on Decision Making MCDA framework was developed to support the prioritization of a broad range of healthcare interventions, with priority given to the intervention that obtains the highest rank. It has evolved and is now in its 10 th edition ${ }^{25}$, yet it is not designed specifically for assessing the value of orphan drugs. MCDA frameworks could also inform on societal preferences, if designed to capture such information. The International Society for Pharmacoeconomics and Outcomes Research Taskforce in multi-criteria decision analysis published recommendations on MCDA, highlighting that MCDA is a tool to support decision-making by HTA bodies and payers ${ }^{26,27}$.

Based on our earlier research ${ }^{28}$, the aim of this study was to further review the literature to establish what criteria are most frequently discussed in the context of assessing orphan drugs with a view to re-testing these criteria on a group of drugs used in the treatment of rare endocrine disorders and to analyze the possible association between the key criteria and the average annual cost of each of the treatments. All the endocrine diseases included in this study are rare (maximum prevalence of 50/100,000 population in Europe $^{29}$ diseases and the drugs included in the study have orphan drug designation although some have lost marketing exclusivity.

\section{Methods}

Targeted literature review

This study entailed two parts, the first being a targeted literature review of Pubmed, Google Scholar and Google to identify any publications featuring MCDAs specifically in orphan drugs and rare diseases from January 1983 to December 2018. Search terms included "multi-criteria decision analysis", "MCDA", "orphan drug", "health technology assessment", and "quality-adjusted life-year".

This time frame was chosen to capture as wide a range of studies as possible and to reflect the start of the Orphan Drug Act in the $\mathrm{USA}^{30}$. The search strategy was restricted to English-language studies and only those reporting on medicines in human use. Each shortlisted study was reviewed to establish what criteria had been used or mentioned in the studies. Criteria were listed by the frequency in which they were reported. The 
second part of the study aimed at testing the eight most reported criteria identified in the literature review by developing a MCDA framework in which to compare the average annual costs of the eight endocrine drugs included in the study with their aggregated MCDA-framework score. The drug cost calculations were based on the average dose according to the Summary of Product Characteristics, taking into account the different body weights for adults and pediatric patient cohorts. Prices were obtained from the British National Formulary (March 2019) and published price lists (March 2019) for the UK and converted to Euros at the December 2018 exchange rate ${ }^{31}$. A further targeted literature review was conducted to source disease- and drugrelated data to populate the MCDA framework for each drug and each criterion. In this search, we looked for the data that would be used to populate the different criteria that would be used in developing the MCDA framework. Only studies that met with the Oxford Centre for Evidence-based Medicine ${ }^{32}$ criteria levels of $1 \mathrm{a}$ to $3 \mathrm{a}$ were included, i.e. Individual case control studies, case series and expert opinion without explicit critical appraisal were excluded. A hand-search of several health technology assessment bodies (National Institute for Health and Care Excellence, Scottish Medicines Consortium, Zorginstituut Nederland, Haute Autorité de santé) was also performed. The data for each drug and each disease was extracted and categorized in tables by each criterion.

\section{Development of the MCDA framework}

In developing the MCDA framework, we had planned to use the ten most cited criteria. However, on reflection, we reduced this to six, on the basis that Disease Rarity (prevalence) is a given when developing assessment frameworks for orphan drugs, as is the Size of the Population. The Quality of the Evidence and Level of Research Undertaken were considered to report the same data and were therefore reported as Level of Research Undertaken. Uncertainty of Effectiveness was deemed to reflect efficacy (or lack thereof) and was not used in this framework. A numerical scoring system was developed for each criterion, as shown in Table 1. For the Disease Severity, the higher score denotes a worse impact of disease on the patient. For the treatment-related criteria, the higher the score, the more marginal the benefit of the treatment is deemed to be. Overall, for the average score of each drug, the lower the score, the better the treatment is. Each criterion (and sub-criterion for Disease Severity) was scored by two people working together, and then checked by two further people to ensure that the same approach was used for all the criteria. Disease Severity is comprised of 4 sub-criteria: Life threatening or life-shortening, Severity of disease symptoms, Mental status due to the disease (anxiety, depression) and Impact of the disease on physical ability. Each subcriterion was scored from 1 to 4 (Table 1) and an average total score was calculated for Disease severity. The data for the subcriterion were based on studies and publications of the included diseases and their overall impact on patients as well as treatment guidelines to establish how treatment should expect to manage the disease and its symptoms ${ }^{33-63}$. The Level of Research Undertaken was scored on an adaptation of the Levels of Evidence from the Oxford Centre for Evidence-based Medicine ${ }^{64}$. Efficacy was scored according to the degree that the primary endpoint was met in the clinical trials (Table 1). The scores for Safety were ranked according to the level of serious adverse events reported in the clinical trials. Unmet Need was defined by the number of other available treatments for each of the endocrine diseases. Similarly, each drug was given a score to represent how many indications the drug was licensed for in total. Criteria scores were compared with the average annual cost of the respective drug, based on list prices published in the British National Formulary for 2019.

\section{Results}

Identification of articles and criteria

Even though this was a targeted literature review, we followed the Preferred Reporting Items for Systematic Reviews and Meta-Analyses method ${ }^{65}$. The literature review identified 161 publications (after removal of duplicates), of which 15 were relevant to our study ${ }^{21,23,25,66-77}$ (Figure 1). A bibliometric analysis described the publication by origin of the primary author (e.g. academic, industry) as shown in Figure 2. First authors were from academia in $53 \%$ of the publications ${ }^{23,66-68,70,73,75,77}$. The first authors in $13 \%$ of the publications were each from consultancy backgrounds ${ }^{72,74}$, government or parastatal origins ${ }^{25,76}$, and healthcare positions ${ }^{69,71}$. A final publication (7\%) was first-authored from industry ${ }^{21}$.

A total of 45 criteria were identified (Table 2). Geographic variation in the importance of the different criteria was observed. For example, in publications in The Netherlands and Germany, the most important criteria in MCDA for orphan drugs were Life-threatening nature of disease and Evidence of clinical efficacy and patient outcome, respectively ${ }^{68}$. As anticipated when focusing on rare diseases, the most frequently cited criterion is Disease severity. This is inevitable, given that many of the rare diseases are life-threatening and result in significant impact on quality of life ${ }^{78}$. The same applies to Unmet Need. By contrast, and rather surprisingly, Treatment convenience was only reported on by $7 \%$ of the studies despite the fact that some drugs may need to be administered regularly by non-oral routes, i.e. injection or intravenously and may impact on overall treatment costs and quality of life. In a landscape where increasingly Innovation (of new treatments) is of significant interest to HTA bodies, it's a criterion that was only reported on by $20 \%$ of the studies.

\section{MCDA framework: Criteria per average annual cost per patient}

The average annual per patient cost in relation to the total drug score is shown in Figure 3 and the comparison of Disease severity score to the average annual cost per patient (Figure 4) highlights the cost differences for diseases with the same severity.

The Unmet Need is a criterion that featured frequently in the literature as would be anticipated in relation to treatments for rare diseases, yet a plot of Unmet Need and the average annual cost suggests there is no discerning relationship based on this single criterion. In contrast, the three products used to treat acromegaly all address the same unmet need, yet considerable variation in average annual cost is observed. 


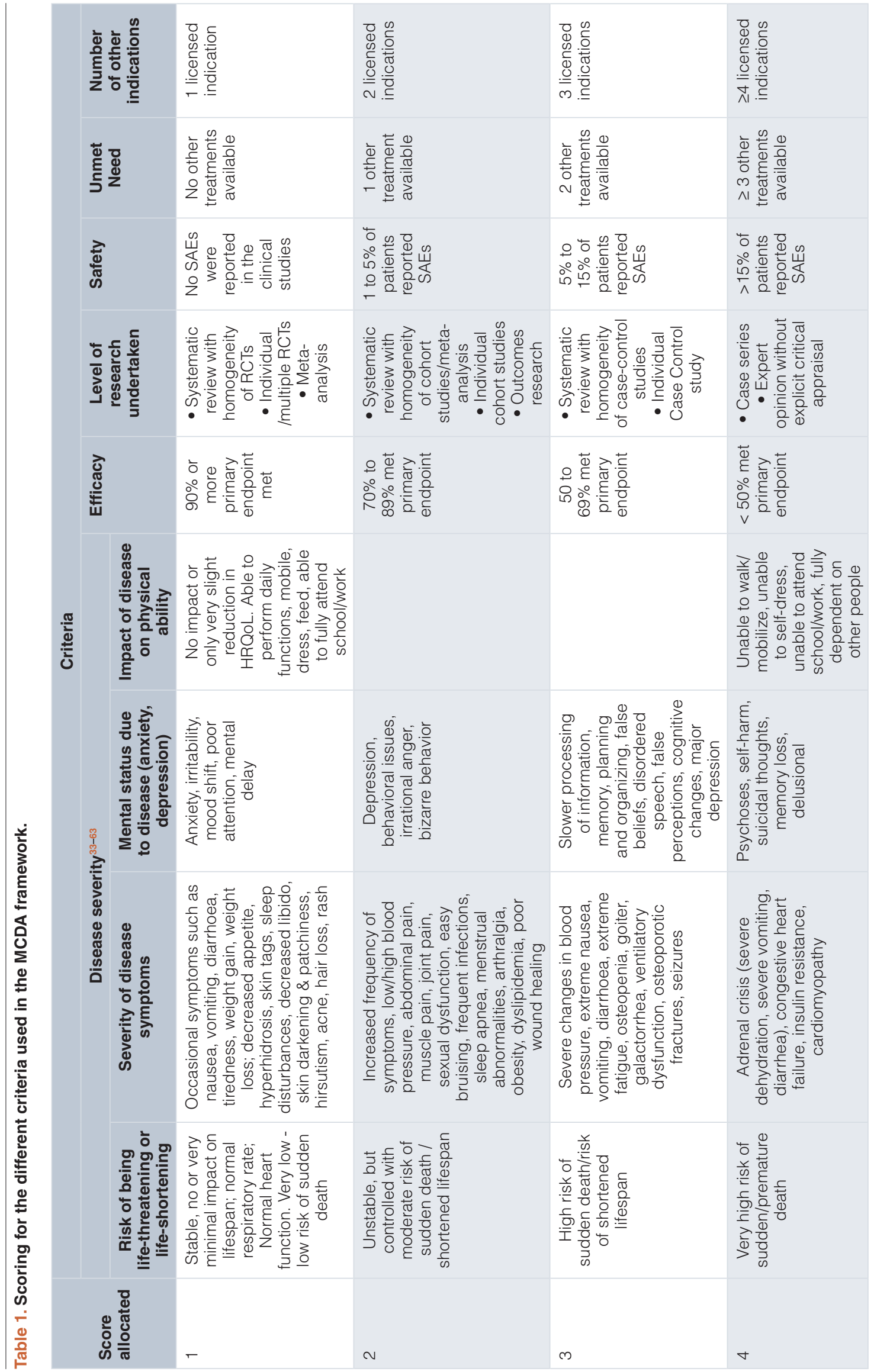




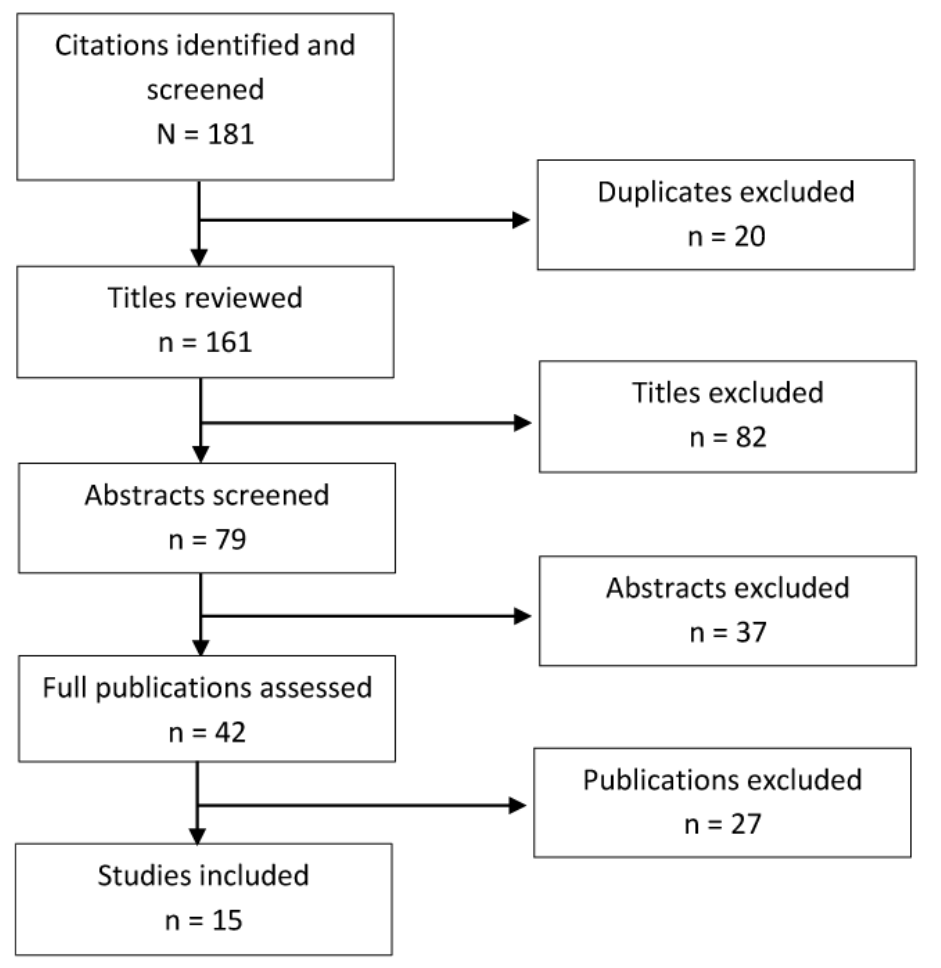

Figure 1. Targeted literature review results.



Figure 2. Bibliometric analysis of primary authorship of the studies included for analysis. 
Table 2. The most cited criteria in the literature.

\begin{tabular}{|l|l|}
\hline Criterion & $\begin{array}{l}\text { Percent reported in } \\
\text { the literature }\end{array}$ \\
\hline Disease severity & $93 \%$ \\
\hline $\begin{array}{l}\text { Unmet Need (or availability of } \\
\text { therapeutic alternatives) }\end{array}$ & $87 \%$ \\
\hline Comparative effectiveness or efficacy & $73 \%$ \\
\hline Quality of evidence & $73 \%$ \\
\hline Safety \& tolerability & $67 \%$ \\
\hline Cost & $60 \%$ \\
\hline Cost-effectiveness & $60 \%$ \\
\hline HRQoL & $53 \%$ \\
\hline Disease rarity (Prevalence) & $47 \%$ \\
\hline Size of affected population & $40 \%$ \\
\hline Treatment impact on condition & $33 \%$ \\
\hline Expert consensus or clinical guidelines & $33 \%$ \\
\hline Complexity of manufacturing & $27 \%$ \\
\hline Level of research undertaken & $27 \%$ \\
\hline Disease burden & $27 \%$ \\
\hline Budget impact & $27 \%$ \\
\hline Type of therapeutic benefit & $27 \%$ \\
\hline Population priority (rare vs non-rare) & $20 \%$ \\
\hline Level of innovation & $20 \%$ \\
\hline Change in life expectancy & $20 \%$ \\
\hline Uniqueness or number of indications & $20 \%$ \\
\hline Life-saving & $20 \%$ \\
\hline
\end{tabular}

The analysis reviewed the relationship between average annual cost and the number of licensed indications that each respective product has. Based on the results of this small sample size of products, the results do not suggest that the average annual cost decreases as a product is licensed for additional indications.

\section{Discussion}

This study sought to assess the key criteria used in MCDA frameworks for orphan drugs and having given each criteria a score based on an ordinal scoring system, to compare the aggregated outcomes for each drug with its average annual per-patient cost without applying different weights (importance) to any criteria. We used the criteria that appeared most in the literature, although because all the diseases studied are rare diseases, the criteria Disease rarity (Prevalence) which was cited by $47 \%$ of the studies, and Size of the affected population (40\%) were not included in this MCDA framework. We observed that there is room for inclusion of others. Notably, the Treatment convenience was not included in the criteria for orphan drugs. In the context of some

\begin{tabular}{|l|l|}
\hline Criterion & $\begin{array}{l}\text { Percent reported in } \\
\text { the literature }\end{array}$ \\
\hline Type of preventive benefit & $20 \%$ \\
\hline Age of patient population & $13 \%$ \\
\hline Societal need or perspective & $13 \%$ \\
\hline Disease impact on family/carers' lives & $13 \%$ \\
\hline Environmental impact & $13 \%$ \\
\hline Type of benefit of intervention & $13 \%$ \\
\hline Level of uncertainty of effectiveness & $13 \%$ \\
\hline Follow-up measures & $13 \%$ \\
\hline Comparative non-medical costs & $13 \%$ \\
\hline $\begin{array}{l}\text { Treatment convenience (route of } \\
\text { administration) }\end{array}$ & $7 \%$ \\
\hline Willingness to pay & $7 \%$ \\
\hline System capacity & $7 \%$ \\
\hline Cure & $7 \%$ \\
\hline Comparative other medical costs & $7 \%$ \\
\hline Mortality & $7 \%$ \\
\hline Progression rate & $7 \%$ \\
\hline Productivity & $7 \%$ \\
\hline $\begin{array}{l}\text { Implementation complexity in existing } \\
\text { healthcare services }\end{array}$ & $7 \%$ \\
\hline Local priorities & $7 \%$ \\
\hline Politics or political focus on disease & $7 \%$ \\
\hline $\begin{array}{l}\text { Disease morbidity and patient clinical } \\
\text { disability with current standard of care }\end{array}$ & $7 \%$ \\
\hline $\begin{array}{l}\text { Spin-off (potential for additional } \\
\text { indications) }\end{array}$ & $7 \%$ \\
\hline Duration of treatment & $7 \%$ \\
\hline
\end{tabular}

complex orphan drug treatments that may be used for the duration of life, such as in the lysosomal storage disorders, the cost and management implications of a drug that has to be administered intravenously on a very regular basis are greater than those of a drug injected subcutaneously once a month (e.g. treatment for acromegaly) or an of a drug taken orally. Therefore, we believe that it is a criterion worth including in MCDA frameworks for orphan drugs.

The Target age (of the treatment population) is a criterion that featured only in two of the studies we reviewed. Indeed, this could be regarded to impact on the assessment of the drug in so much as it may result in absenteeism from school for children and work for parent(s) caring for ill children. Access to orphan drug treatment could have significant impact on education attainment and productivity.

The Level of research undertaken prior to licensing of a drug is likely to establish the drug's efficacy and safety with a view 


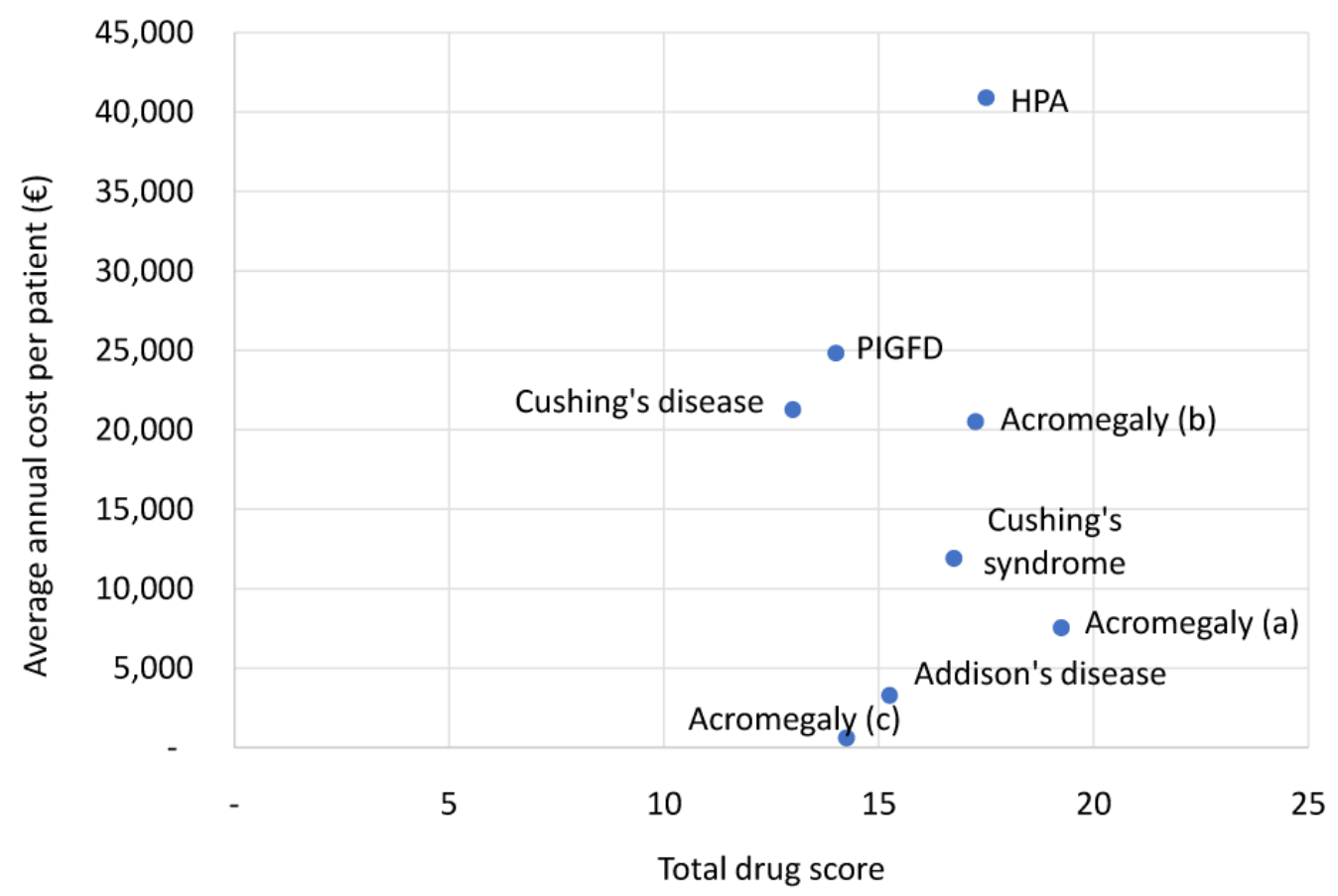

Please note that Cushing's syndrome and Cushing's disease are not the same illness. HPA: hyperphenylalaninaemia; PGFID: primary insulin-like growth factor-1 deficiency

Figure 3. Comparison of the total drug score with the average annual per-patient drug treatment cost.

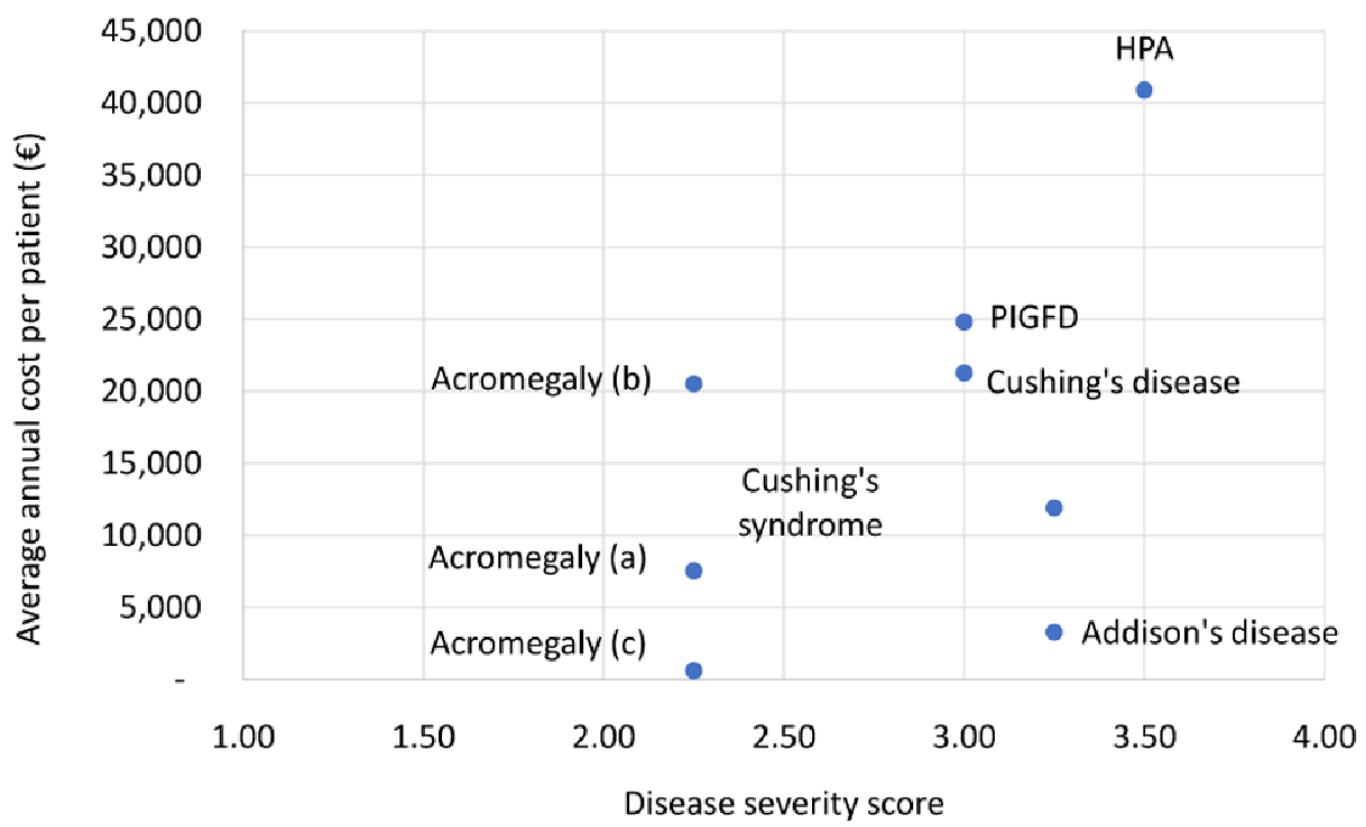

Please note that Cushing's syndrome and Cushing's disease are not the same illness. HPA: hyperphenylalaninaemia; PGFID: primary insulin-like growth factor-1 deficiency

Figure 4. Disease severity compared to average annual per-patient cost. 
to reducing the level of uncertainty. However, we question the comparability of the level of research between products. To our knowledge, no studies have suggested a methodology to score the duration of studies versus the population size of a study. For example, would a study performed in a small population sample over several years earn a higher score than one conducted on several thousand patients over less than a year? In the scope of drugs used for rare diseases, the population size of a study is frequently very small due to the low prevalence of the disease. In diseases where there is no other treatment option, it may be necessary to reduce the impact or weight of this criterion in order to facilitate access to the medication. Irrespective of the level of research, it was seen to have little correlation with the average annual per-patient cost of each drug.

While some other studies have shown an inverse relationship between Disease rarity and price ${ }^{79,80}$, this study was not designed to analyze this relationship. However, it provided the opportunity for a within therapy comparison of treatments for acromegaly. One might expect treatments for the same disease to have a narrow average annual per-patient cost range. Nevertheless, the average annual prices range from $€ 617$ to $€ 20,520$ demonstrating that whilst disease severity is the same for two or more drugs for the same indication, their costs may vary widely.

The criteria can be measured on various scales: binary, nominal, ordinal, cardinal or ratio ${ }^{81}$. For simplicity and transparency, we chose a numerical scoring system whereby the data for each criterion in the framework are converted into consistent numerical values from which an overall score is calculated. In their pilot study to test a MCDA for orphan drugs, Sussex et al. ${ }^{74}$ used a numerical rating scale from 1 (worst score) to 7 (best score). Their rationale was that it permitted sufficient discrimination between levels for each criterion. By contrast, Hughes-Wilson et al. ${ }^{21}$ suggested a simplistic three-level scale. One of the limitations of the model might be the application of the scores to the criteria, and the subjectivity of those scores. However, as each criterion was treated equally and scored by the same team, the differences are likely to be minimal on the overall results.

The literature review highlights some of the limitations of MCDAs. Defining the criteria at the outset is crucial to ensure that overlap between criteria are avoided. As in this study, we chose to avoid confounding the overall score by excluding Disease rarity and Size of the population. It is essential that the criteria are not selected merely to favor a preferred outcome. Ultimately, disease rarity in itself should not be the reason for paying premium prices. Other factors, such as severity of the disease, may be more important ${ }^{82}$. Furthermore, it is unlikely that all criteria should carry the same importance (weight ${ }^{23}$, and as yet, very little work has been done to elucidate weighting preferences in a way that could best inform in healthcare reimbursement decisions. Weighting the criteria may be complicated, and dependent on the perspective of the assessment ${ }^{21}$.

Given that the criteria used might vary from one health economy to another, and similarly the importance of these criteria perceived differently, the MCDA framework will not necessarily lead to the same reimbursement decisions across different countries. Choices of criteria and weighting might be influenced by the health policy focus and the inclusion of the societal perspective $^{83}$.

Since regulatory organizations, such as the Haute Autorité de Santé $^{84}$ in France, have indicated that drug innovation is valued in assessing drugs, it is interesting to observe that Level of innovation did not feature more frequently in the literature. It should serve as a powerful criterion in the judgement of drugs, especially in the current climate of priority setting, not only for orphan drugs but equally for all other drugs too.

In their work on MCDAs, Hughes-Wilson et al. ${ }^{21}$ highlighted the need for several key criteria that should form part of an MCDA tool for orphan drugs. One such criterion is the Manufacturing complexity. Our study found this criterion to be reported by $27 \%$ of the literature review results. In the landscape of plasma-derived medicines (clotting factors, immunoglobulins) that are reputed to be more complex in their manufacturing processes $^{85,86}$ it is likely that this criterion will feature more prominently if MCDAs are to become useful assessment tools in drug assessments.

The scoring systems for each of the criteria that were adopted in this study were of the numerical form, with equal importance between grades. Despite potential criticism about the imprecision of a simple numerical scoring system, the rationale for its use is due to its simplicity and that it does not require an expert panel to adjudicate the value of one criterion against another, as would be the case in outranking methods ${ }^{87}$, satisficing methods $^{20}$ and value measurement methods ${ }^{20}$. Furthermore, it does not require the use of special computer software. Similarly, the same rationale applies to lack of using any weighting or preferences for a particular criterion, since the primary aim was to apply the key identified criteria as a tool for within therapy and across therapy comparisons. Since the methodology was applied uniformly across the criteria and drugs in the study, the outcomes provide valuable tools for comparison. However, the aim of the study was to demonstrate the trends and above all, to highlight the need for a different approach to assessing orphan drugs.

\section{Conclusion}

To date much work has been done in describing MCDAs and the criteria which could be considered core to value despite the evident lack of relationship between Disease severity and the overall drug score derived in the MCDA framework. Whilst no consensus on their design and applicability has yet been reached, MCDAs are frameworks that are worth adopting in the assessment of orphan drugs, specifically because they include disease-related and drug-related criteria that are likely to impact on patients and the healthcare system. They are not intended to replace the current HTA methodologies, but should certainly be used in conjunction to assist in decision making processes and prioritizing allocation of healthcare resources.

\section{Data availability}

All data underlying the results are available as part of the article and no additional source data are required. 
1. European Observatory on Health Systems and Policies Series: Regulating pharmaceuticals in Europe: striving for efficiency, equity and quality. [Accessed 6 January 201920046 January 2019]. Reference Source

2. Wise J: NHS and Vertex remain deadlocked over price of cystic fibrosis drug. BMJ. 2019; 364: I1094.

PubMed Abstract | Publisher Full Text

3. McKee S: Four new medicines cleared for use on NHS Scotland. 2018 Reference Source

4. European Biotechnology: Big Pharma pushing up orphan drug prices. 2017; [cited Accessed January 2019]. Reference Source

5. Burns J: Orphan Drugs:Way Too Many, Way too Expensive. Manag Care. 2017; 26(6): 12-17 PubMed Abstract

6. National Institute for Health and Care Excellence (NICE): Patient access schemes liaison unit. 2019; [cited Accessed March 2019]. Reference Source

7. National Institute for Health and Care Excellence (NICE): HST2: Elosulfase alfa for treating mucopolysaccharidosis type IVa. 2015; [cited Accessed March 2019]. Reference Source

8. Diaby V, Goeree R, Hoch J, et al.: Multi-criteria decision analysis for health technology assessment in Canada: insights from an expert panel discussion. Expert Rev Pharmacoecon Outcomes Res. 2015; 15(1): 13-9.

PubMed Abstract | Publisher Full Text

9. Wilsdon T, Fiz E, H A: A comparative analysis of the role and impact of Health Technology Assessment. 2013

Reference Source

10. Shire Plc: Policy Principles for Value Assessment of Rare Disease Treatments 2019; [cited Accessed February 2019]. Reference Source

11. Cystic Fibrosis Trust: NICE rejects Orkambi. 2016; [cited 2019 March] Reference Source

12. Pettitt DA, S R, Smith J: The Limitations of QALY: A Literature Review. J Stem Cell Res Ther (Edmond). 2016; 6(4): 1000334.

Publisher Full Text

13. Drummond M, Evans B, LeLorier J, et al.: Evidence and values: requirements fo public reimbursement of drugs for rare diseases--a case study in oncology. Can J Clin Pharmacol. 2009; 16(2): e273-81; discussion e282-4. PubMed Abstract

14. Orenstein M, Barbouth D, Bodamer OA, et al.: Patients with type 1 Gaucher disease in South Florida, USA: demographics, genotypes, disease severity and treatment outcomes. Orphanet J Rare Dis. 2014; 9: 45 PubMed Abstract | Publisher Full Text | Free Full Text

15. Day S, Jonker AH, Lau LPL, et al.: Recommendations for the design of small population clinical trials. Orphanet J Rare Dis. 2018; 13(1): 195. Publisher Full Text

16. Rothera M: European Policies for Rare Disease Patients: Workshop Improving Access to Orphan Drugs in Europe. 2011; [cited August 2016] Reference Source

17. Hilgers RD, Roes K, Stallard N, et al:: Directions for new developments on statistical design and analysis of small population group trials. Orphanet $J$ Rare Dis. 2016; 11(1): 78

PubMled Abstract | Publisher Full Text | Free Full Text

18. Boudes PF: Clinical studies in lysosomal storage diseases: Past, present, and future. Rare Dis. 2013; 1: e26690.

PubMed Abstract | Publisher Full Text | Free Full Text

19. Cleemput I, et al.: Threshold values for cost-effectiveness in health care. 2008 [cited Accessed March 2019].

Reference Source

20. Thokala $\mathrm{P}$, Duenas A: Multiple criteria decision analysis for health technology assessment. Value Health. 2012; 15(8): 1172-81. assessment. Value Health. 2012; 15(8):

21. Hughes-Wilson W, Palma A, Schuurman A, et al:: Paying for the Orphan Drug System: break or bend? Is it time for a new evaluation system for payers in Europe to take account of new rare disease treatments? Orphanet $J$ Rare Dis. 2012; 7: 74 .

PubMed Abstract | Publisher Full Text | Free Full Text

22. Bourdoncle $\mathrm{M}$, Juillard-Condat $\mathrm{B}$, Taboulet $\mathrm{F}$ : Patient access to orphan drugs in France. Orphanet J Rare Dis. 2019; 14(1): 47. PubMled Abstract | Publisher Full Text | Free Full Text

23. Iskrov G, Miteva-Katrandzhieva T, Stefanov R: Multi-Criteria Decision Analysis for Assessment and Appraisal of Orphan Drugs. Front Public Health. 2016; 4 214.

PubMed Abstract | Publisher Full Text | Free Full Text

24. Communities and Local Government Publications: Multi-criteria analysis: a manual. 2009; [cited January 2019].

Reference Source
25. EVIDEM: EVIDEM. 2017

Reference Source

26. Thokala P, Devlin N, Marsh K, et al:: Multiple Criteria Decision Analysis for Health Care Decision Making--An Introduction: Report 1 of the ISPOR MCDA Emerging Good Practices Task Force. Value Health. 2016; 19(1): 1-13. PubMed Abstract | Publisher Full Text

27. Marsh K, IJzerman M, Thokala P, et al:: Multiple Criteria Decision Analysis for Health Care Decision Making--Emerging Good Practices: Report 2 of the ISPOR MCDA Emerging Good Practices Task Force. Value Health. 2016; 19(2): 125-37.

PubMed Abstract | Publisher Full Text

28. Schey C, Irwin J, Teneishvili M, et al:: Assessing the relationship between individual attributes identified in review of multi-criteria decision analysis (MCDA) of rare diseases and annual treatment costs in rare endocrine disorders. Value in Health. 2014; 17(7): A562.

Publisher Full Text

29. EURORDIS: About Rare Diseases. 2019 Reference Source

30. FDA: Public Law 97-414. 1983; [cited January 2019].; Reference Source

31. Exchange Rates. 2018 Reference Source

32. The Centre for Evidence-Based Medicine. 2019; [cited 2019 March] Reference Source

33. Lambert JK, Goldberg L, Fayngold S, et al:: Predictors of mortality and longterm outcomes in treated Cushing's disease: a study of 346 patients. $J$ Clin Endocrinol Metab. 2013; 98(3): 1022-30.

PubMed Abstract | Publisher Full Text | Free Full Text

34. van Haalen FM, Broersen LH, Jorgensen JO, et al: Management of endocrine disease: Mortality remains increased in Cushing's disease despite biochemical remission: a systematic review and meta-analysis. Eur $J$ Endocrinol. 2015; 172(4): R143-9.

PubMed Abstract | Publisher Full Text

35. Santos A, Resmini E, Martínez Momblán MA, et al:: Quality of Life in Patients With Cushing's Disease. Front Endocrinol (Lausanne). 2019; 10: 862 PubMed Abstract | Publisher Full Text | Free Full Text

36. Gkourogianni A, Sinaii N, Jackson SH, et al:: Pediatric Cushing disease: disparities in disease severity and outcomes in the Hispanic and AfricanAmerican populations. Pediatr Res. 2017; 82(2): 272-277. PubMed Abstract | Publisher Full Text | Free Full Text

37. van Aken MO, Pereira AM, Biermasz NR, et al:: Quality of life in patients afte long-term biochemical cure of Cushing's disease. $J$ Clin Endocrinol Metab. 2005; 90(6): 3279-86.

PubMed Abstract | Publisher Full Text

38. Yaneva M, Kalinov K, Zacharieva S: Mortality in Cushing's syndrome: data from 386 patients from a single tertiary referral center. Eur J Endocrinol. 2013; 169(5): $621-7$.

PubMed Abstract | Publisher Full Text

39. Mayo Clinic: Cushing Syndrome. 2019; [cited February 2019]. Reference Source

40. Sonino N, Boscaro M, Fallo F, et al:: A clinical index for rating severity in Cushing's syndrome. Psychother Psychosom. 2000; 69(4): 216-20. PubMed Abstract | Publisher Full Text

41. Braun LT, Riester A, Oßwald-Kopp A, et al:: Toward a Diagnostic Score in Cushing's Syndrome. Front Endocrinol (Lausanne). 2019; 10: 766. PubMed Abstract | Publisher Full Text | Free Full Text

42. Stieg MR, Auer MK, Berr C, et al.: Clinical score system in the treatment of Cushing's disease: failure to identify discriminative variables from the German Cushing's Registry. Pituitary. 2019; 22(2): 129-136.

PubMed Abstract | Publisher Full Text

43. Foundation, C.G: Primary IGF-1 Deficiency. 2017; [cited February 2020]. Reference Source

44. Orphanet: Growth delay due to insulin-like growth factor type 1 deficiency. 2020; [cited February 2020]. Reference Source

45. Grimberg A, DiVall SA, Polychronakos C, et al.: Guidelines for Growth Hormone and Insulin-Like Growth Factor-I Treatment in Children and Adolescents: Growth Hormone Deficiency, Idiopathic Short Stature, and Primary Insulin-Like Growth Factor-I Deficiency. Horm Res Paediatr. 2016; 86(6): 361-397. PubMed Abstract | Publisher Full Text

46. Savage MO: Phenotypes, investigation and treatment of primary IGF-1 deficiency. Endocr Dev. 2013; 24: 138-49. PubMed Abstract | Publisher Full Text

47. Database, R.D: Acromegaly. 2019; [cited March 2019]. Reference Source

48. Guitelman M, Abreu A, Espinosa-de-los-Monteros AL, et al.: Patient-focussed outcomes in acromegaly. Pituitary 2014: 17(Suppl 1): S18-23. PubMed Abstract | Publisher Full Text | Free Full Text 
49. Katznelson L, Laws ER Jr, Melmed S, et al:: Acromegaly: an endocrine society clinical practice guideline. J Clin Endocrinol Metab. 2014; 99(11): 3933-51. PubMed Abstract | Publisher Full Text

50. Rowles SV, Prieto L, Badia X, et al.: Quality of life (QOL) in patients with acromegaly is severely impaired: use of a novel measure of QOL: acromegaly quality of life questionnaire. J Clin Endocrinol Metab. 2005; 90(6): 3337-41. PubMed Abstract | Publisher Full Text

51. Lugo G, Pena L, Cordido F: Clinical manifestations and diagnosis of acromegaly. Int J Endocrinol. 2012; 2012: 540398 . PubMed Abstract | Publisher Full Text | Free Full Text

52. Lobatto DJ, Steffens ANV, Zamanipoor Najafabadi AH, et al:: Work disability and its determinants in patients with pituitary tumor-related disease. Pituitary. 2018; 21(6): 593-604.

PubMed Abstract | Publisher Full Text | Free Full Text

53. Rare Disease Database: Addison's Disease. 2019; [cited February 2019]. Reference Source

54. Sievers C, Dimopoulou C, Pfister $\mathrm{H}$, et al.: Prevalence of mental disorders in acromegaly: a cross-sectional study in $\mathbf{8 1}$ acromegalic patients. Clin Endocrinol (Oxf). 2009; 71(5): 691-701.

PubMed Abstract | Publisher Full Text

55. Riedel M, Wiese A, Schürmeyer TH, et al:: Quality of life in patients with Addison's disease: effects of different cortisol replacement modes. Exp Clin Endocrinol. 1993; 101(2): 106-11.

PubMed Abstract | Publisher Full Text

56. Kluger N, Matikainen N, Sintonen $\mathrm{H}$, et al:: Impaired health-related quality of life in Addison's disease--impact of replacement therapy, comorbidities and socioeconomic factors. Clin Endocrinol (Oxf). 2014; 81(4): 511-8.

PubMed Abstract | Publisher Full Text

57. Petersen KS, Rushworth RL, Clifton PM, et al.: Recurrent nocturnal hypoglycaemia as a cause of morning fatigue in treated Addison's disease-favourable response to dietary management: a case report. BMC Endocr Disord. 2015; 15: 61.

PubMed Abstract | Publisher Full Text | Free Full Text

58. de Baulny HO, Abadie V, Feillet F, et al:: Management of phenylketonuria and hyperphenylalaninemia. J Nutr. 2007; 137(6 Suppl 1): 1561S-1563S; discussion 1573S-1575S

PubMed Abstract | Publisher Full Text

59. Mitchell JJ, Trakadis YJ, Scriver CR: Phenylalanine hydroxylase deficiency. Genet Med. 2011; 13(8): 697-707. PubMed Abstract | Publisher Full Text

60. Campistol J, Gassió R, Artuch R, et al: Neurocognitive function in mild hyperphenylalaninemia. Dev Med Child Neurol. 2011; 53(5): 405-8. PubMed Abstract | Publisher Full Text

61. Ashe K, Kelso W, Ferrand S, et al:: Psychiatric and Cognitive Aspects of Phenylketonuria: The Limitations of Diet and Promise of New Treatments. Front Psychiatry. 2019; 10: 561

PubMed Abstract | Publisher Full Text | Free Full Text

62. Publishing, H: Severe Mental IIIness Defined by Duration and Disability. 2016; [cited February 2019].

Reference Source

63. Zimmerman M, Morgan TA, Stanton K: The severity of psychiatric disorders. World Psychiatry. 2018; 17(3): 258-275.

PubMed Abstract | Publisher Full Text | Free Full Text

64. Oxford Centre for Evidence-based Medicine: Levels of Evidence. 2009. Reference Source

65. Liberati A, Altman DG, Tetzlaff J, et al.: The PRISMA statement for reporting systematic reviews and meta-analyses of studies that evaluate healthcare interventions: explanation and elaboration. BMJ. 2009; 339: b2700. PubMed Abstract | Publisher Full Text | Free Full Text

66. Baran-Kooiker A, Czech M, Kooiker C: Multi-Criteria Decision Analysis (MCDA) Models in Health Technology Assessment of Orphan Drugs-a Systematic Literature Review. Next Steps in Methodology Development? Front Public Health. 2018; 6: 287.

PubMed Abstract | Publisher Full Text | Free Full Text

67. Defechereux T, Paolucci F, Mirelman A, et al:: Health care priority setting in Norway a multicriteria decision analysis. BMC Health Serv Res. 2012; 12: 39. PubMed Abstract | Publisher Full Text | Free Full Text

68. Friedmann $\mathrm{C}$, Levy $\mathrm{P}$, Hensel $\mathrm{P}$, et al: Using multi-criteria decision analysis to appraise orphan drugs: a systematic review. Expert Rev Pharmacoecon Outcomes Res. 2018; 18(2): 135-146.

PubMed Abstract | Publisher Full Tex

69. Gilabert-Perramon A, Torrent-Farnell J, Catalan A, et al:: DRUG EVALUATION AND
DECISION MAKING IN CATALONIA: DEVELOPMENT AND VALIDATION OF A METHODOLOGICAL FRAMEWORK BASED ON MULTI-CRITERIA DECISION ANALYSIS (MCDA) FOR ORPHAN DRUGS. Int $J$ Technol Assess Health Care.

2017; 33(1): 111-120.

PubMed Abstract | Publisher Full Tex

70. Goetghebeur MM, Wagner M, Samaha D, et al.: EXPLORING VALUES OF HEALTH TECHNOLOGY ASSESSMENT AGENCIES USING REFLECTIVE MULTICRITERIA AND RARE DISEASE CASE. Int $J$ Technol Assess Health Care. 2017; 33(4): 504-520.

PubMed Abstract | Publisher Full Text

71. Jiménez A, Ais A, Beaudet A, et al:: Determining the value contribution of selexipag for the treatment of pulmonary arterial hypertension (PAH) in Spain using reflective multi-criteria decision analysis (MCDA). Orphanet $J$ Rare Dis. 2018; 13(1): 220

PubMed Abstract | Publisher Full Text | Free Full Text

72. Marsh K, Lanitis T, Neasham D, et al:: Assessing the value of healthcare interventions using multi-criteria decision analysis: a review of the literature. Pharmacoeconomics. 2014; 32(4): 345-65.

PubMed Abstract | Publisher Full Text

73. Schey C, Krabbe PF, Postma MJ, et al:: Multi-criteria decision analysis (MCDA) testing a proposed MCDA framework for orphan drugs. Orphanet $J$ Rare Dis. 2017; 12(1): 10.

PubMed Abstract | Publisher Full Text | Free Full Text

74. Sussex J, Rollet P, Garau M, et al:: A pilot study of multicriteria decision analysis for valuing orphan medicines. Value Health. 2013; 16(8): 1163-9. PubMed Abstract | Publisher Full Text

75. Trip AM, Tsiachristas A, Koenders JM, et al.: Multi-Criteria Decision Analysis for Reimbursing Orphan Drugs: A Dutch Demonstration Study Using the Analytic Hierarchy Process Method. Value Health. 2014; 17(7): A541-2.

PubMed Abstract | Publisher Full Text

76. Cleemput I, Devriese S, Christiaens W, et al:: Multi-criertia decision analysis for the appraisal of medical needs: A pilot study. KCE REPORT $272 \mathrm{HEALTH}$ SERVICES RESEARCH. 2016 Reference Source

77. Lockhart C: Value Assessment of Orphan Drugs and Treatments for Rare Diseases. 2016.

Reference Source

78. Federal Office of Public Health: Numerous rare diseases with many people affected. 2019.

Reference Source

79. Medic G, Korchagina D, Young KE, et al:: Do payers value rarity? An analysis of the relationship between disease rarity and orphan drug prices in Europe. J Mark Access Health Policy. 2017; 5(1): 1299665. PubMed Abstract | Publisher Full Text | Free Full Text

80. Messori A, Cicchetti A, Patregani L: Orphan drugs. Relating price determination to disease prevalence. BMJ. 2010; 341: $c 4615$.

PubMed Abstract | Publisher Full Text

81. Johri M, Norheim OF: Can cost-effectiveness analysis integrate concerns for equity? Systematic review. Int J Technol Assess Health Care. 2012; 28(2): $125-32$.

PubMled Abstract | Publisher Full Text

82. National Institute for Health and Care Excellence: NICE CITIZENS COUNCIL REPORT ULTRA ORPHAN DRUGS. 2004. Reference Source

83. Kanters TA, Hakkaart L, Rutten-van Mölken MP, et al.: Access to orphan drugs in western Europe: can more systematic policymaking really help to avoid different decisions about the same drug? Expert Rev Pharmacoecon Outcomes Res. 2015; 15(4): 557-9. PubMed Abstract | Publisher Full Text

84. Haute Autorité de Santé: Innovation et recherche. 2019. Reference Source

85. Winge S, Yderland L, Kannicht C, et al:: Development, upscaling and validation of the purification process for human-cl rhFVIII (Nuwiq ${ }^{\circledR}$ ), a new generation recombinant factor VIII produced in a human cell-line. Protein Expr Purif. 2015; 115: $165-75$.

PubMed Abstract | Publisher Full Text

86. Farrugia A, Quinti I: Manufacture of immunoglobulin products for patients with primary antibody deficiencies - the effect of processing conditions on product safety and efficacy. Front Immunol. 2014; 5: 665 PubMed Abstract | Publisher Full Text | Free Full Text

87. Mousseau $\mathrm{V}$, Dias L: Valued outranking relations in ELECTRE providing manageable disaggregation procedures. Eur J Oper Res. 2004; 156(2): 476-482. Publisher Full Text 


\section{Open Peer Review}

\section{Current Peer Review Status:}

\section{Version 1}

Reviewer Report 08 September 2020

https://doi.org/10.5256/f1000research.23953.r70233

(c) 2020 Zaliska O. This is an open access peer review report distributed under the terms of the Creative Commons Attribution License, which permits unrestricted use, distribution, and reproduction in any medium, provided the original work is properly cited.

\section{Olha Zaliska}

Department of Management and Economy of Pharmacy, Medicine Technology and Pharmacoeconomics, Faculty of Postgraduate Education, Danylo Halytsky Lviv National Medical University, Lviv, Ukraine

The manuscript, "The application of multi-criteria decision analysis to inform in resource allocation" contens the new results of systematic analysis of MCDA in rare diseases in published literature. The authors found the five most frequently mentioned criterias were disease severity, unmet need, comparative effectiveness/efficacy, quality of evidence, and safety \& tolerability. The study then plots per patient costs comparing total drug score and disease severity to demonstrate the wide range in costs.

\section{Overall comments:}

This is a great contribution for MCDA area and needed for the field to move forward with adopting MCDA in rare diseases. I agree the use of MCDA is an add-on to most HTA processes, especially for expensive orphan drugs.

Authors can use citation the abstract "Eliciting Payers Preferences In Central And Eastern Europe: Results Of MCDA Case Study" ( Piniazhko O., Zalis'ka O., Zah V., 2016¹).

I believe you can expand results for many stakeholders.

\section{References}

1. Piniazhko O, Zalis'ka O, Zah V: Eliciting Payers Preferences In Central And Eastern Europe: Results Of Mcda Case Study. Value in Health. 2016; 19 (7). Publisher Full Text

Is the work clearly and accurately presented and does it cite the current literature? Yes

Is the study design appropriate and is the work technically sound? Yes

Are sufficient details of methods and analysis provided to allow replication by others? 
Yes

If applicable, is the statistical analysis and its interpretation appropriate? Yes

Are all the source data underlying the results available to ensure full reproducibility? Yes

Are the conclusions drawn adequately supported by the results?

Yes

Competing Interests: No competing interests were disclosed.

Reviewer Expertise: Pharmacoeconomic analysis. HTA, MCDA, HEOR, marketing, education

I confirm that I have read this submission and believe that I have an appropriate level of expertise to confirm that it is of an acceptable scientific standard.

Reviewer Report 09 June 2020

https://doi.org/10.5256/f1000research.23953.r63937

(c) 2020 McQueen R. This is an open access peer review report distributed under the terms of the Creative Commons Attribution License, which permits unrestricted use, distribution, and reproduction in any medium, provided the original work is properly cited.

\section{Robert Brett McQueen}

Skaggs School of Pharmacy and Pharmaceutical Sciences, University of Colorado Anschutz Medical Campus, Aurora, CO, USA

The manuscript, "The application of multi-criteria decision analysis to inform in resource allocation" is an exploration of current attributes for MCDA in rare diseases through a targeted literature review and suggested MCDA framework specific to rare disease. The study found the five most frequently mentioned attributes were disease severity, unmet need, comparative effectiveness/efficacy, quality of evidence, and safety \& tolerability. The study then plots per patient costs against total drug score and disease severity to demonstrate the wide range in costs.

Overall comments:

This is a nice contribution and needed for the field to move forward with adopting MCDA. I agree the use of MCDA is an add-on to most HTA processes. However, I believe you can expand on some areas and I have a two main suggestions for consideration:

1) Your work is mainly focused on the performance metrics of orphan drugs that are based on literature-derived criteria. For example, your discussion comment, "Defining the criteria at the outset is crucial to ensure that overlap between criteria are avoided." This is quite key to informing 
MCDA scoring/frameworks and flows directly into measurement and weighting of the criteria. On measurement, instead of simply listing this as a limitation can you provide any suggestions to future researchers on how to define the levels within criteria a priori instead of depending on past literature? Is it worth identifying criteria through engaging with patients, providers, etc. on criteria that may not be driven by regulatory approval? Meaning is there value in developing (and eventually weighting) criteria using ex ante preferences? This could aid in evidence generation, societal preference alignment, etc. Maybe that was the point you were making but didn't seem to be clear to me.

2) Related to 1), importance/weighting is quite complicated and should have it's own dedicated paragraph. Not only does an overall MCDA depend on perspective as you note in the Discussion, certain criteria may depend on perspective, i.e., clinical benefits are largely accrued by patients but cost is accrued by health systems. So it may be wise to dig in a bit more here with a separate paragraph noting these challenges. Weighting itself also comes with multiple methods that vary in bias.

Is the work clearly and accurately presented and does it cite the current literature? Yes

Is the study design appropriate and is the work technically sound? Yes

Are sufficient details of methods and analysis provided to allow replication by others? Yes

If applicable, is the statistical analysis and its interpretation appropriate? Yes

Are all the source data underlying the results available to ensure full reproducibility? Yes

Are the conclusions drawn adequately supported by the results? Yes

Competing Interests: My institution on my behalf has received grant funding to explore the use of MCDA as a supplement to HTA in the United States.

Reviewer Expertise: Health economics

I confirm that I have read this submission and believe that I have an appropriate level of expertise to confirm that it is of an acceptable scientific standard, however I have significant reservations, as outlined above.

Author Response 29 Nov 2020

Carina Schey, Global Market Access Solutions Sàrl, St-Prex, Switzerland 
Dear Prof. McQueen,

Many thanks for your thorough review of the manuscript and valuable insights, which I had addressed in a subsequent publication. However, I shall also address it in this manuscript.

Engaging with patients in evidence generation is to meet the increasing awareness of representing the patient needs, a feature of reimbursement decisions that has increased in recent years in several European markets.

The issues of weighting, as you aptly point out, are complex and open to "over-counting" if criteria overlap in anyway, or are already accounted for in the orphan drug incentives (such as disease rarity, which alone is not a good enough reason to reimburse a drug).

Ultimately, the issue is not one of favouring MCDA over cost-effectiveness (or vice versa), but rather an ever-increasing dilemma of affordability and sustainability of healthcare provision especially in light of the horrifically expensive gene therapies coming to market amidst substantial uncertainty of their long-term benefits and other effects. Interesting times ahead!

Kind regards

Carina

Competing Interests: No conflicting interests.

The benefits of publishing with F1000Research:

- Your article is published within days, with no editorial bias

- You can publish traditional articles, null/negative results, case reports, data notes and more

- The peer review process is transparent and collaborative

- Your article is indexed in PubMed after passing peer review

- Dedicated customer support at every stage

For pre-submission enquiries, contact research@f1000.com 